\title{
De evolutie van de Beneden-Schelde in België en Zuidwest-Nederland na de laatste ijstijd
}

The evolution of the Lower Scheldt River in Belgium and the Southwestern Netherlands after the last Ice Age

\section{Patrick Kiden}

\section{(2) OpenEdition}

\section{Journals}

Édition électronique

URL : http://journals.openedition.org/belgeo/12025

DOI : $10.4000 /$ belgeo.12025

ISSN : 2294-9135

Éditeur :

National Committee of Geography of Belgium, Société Royale Belge de Géographie

Édition imprimée

Date de publication : 30 septembre 2006

Pagination : 279-294

ISSN : 1377-2368

Référence électronique

Patrick Kiden, « De evolutie van de Beneden-Schelde in België en Zuidwest-Nederland na de laatste ijstijd », Belgeo [Online], 3 | 2006, Online op 30 octobre 2013, geraadpleegd op 21 avril 2019. URL : http://journals.openedition.org/belgeo/12025; DOI : 10.4000/belgeo.12025

Ce document a été généré automatiquement le 21 avril 2019

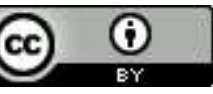

Belgeo est mis à disposition selon les termes de la licence Creative Commons Attribution 4.0 International. 


\section{De evolutie van de Beneden-Schelde in België en Zuidwest-Nederland na de laatste ijstijd}

The evolution of the Lower Scheldt River in Belgium and the Southwestern Netherlands after the last Ice Age

\section{Patrick Kiden}

\section{Inleiding}

1 In de voorbije vijftien jaar is de kennis van de postglaciale ontwikkeling van de Schelde sterk toegenomen. Zo is vooral vanaf 1990 veel bekend geworden over de Schelde in Zuidwest-Nederland (Zeeland), en over de invloed van de zeespiegelstijging op de ontwikkeling van de Schelde. Deze bijdrage geeft een overzicht van een aantal van deze nieuwe resultaten en inzichten in verband met de evolutie van de Schelde in het Laatglaciaal en het Holoceen. Daarbij worden enkel de Beneden-Schelde - het deel van de Schelde stroomafwaarts van Gent - en de Scheldeloop in Nederland beschouwd (Fig. 1), waarmee thematisch het onderwerp ook beperkt is tot dat deel van de rivier waarvan de postglaciale ontwikkeling in min of meer sterke mate door de Holocene zeespiegelstijging is beïnvloed. Omdat het calibreren van ${ }^{14} \mathrm{C}$-dateringen in dit tijdsbereik geen problemen meer stelt en het gebruik van een lineaire tijdschaal wenselijk is, zijn alle in deze bijdrage vermelde ouderdommen en jaartallen uitgedrukt in kalenderjaren. 
Figuur 1. Het Beneden-Scheldebekken in België en Nederland, met een aantal lokaties vermeld in de tekst.

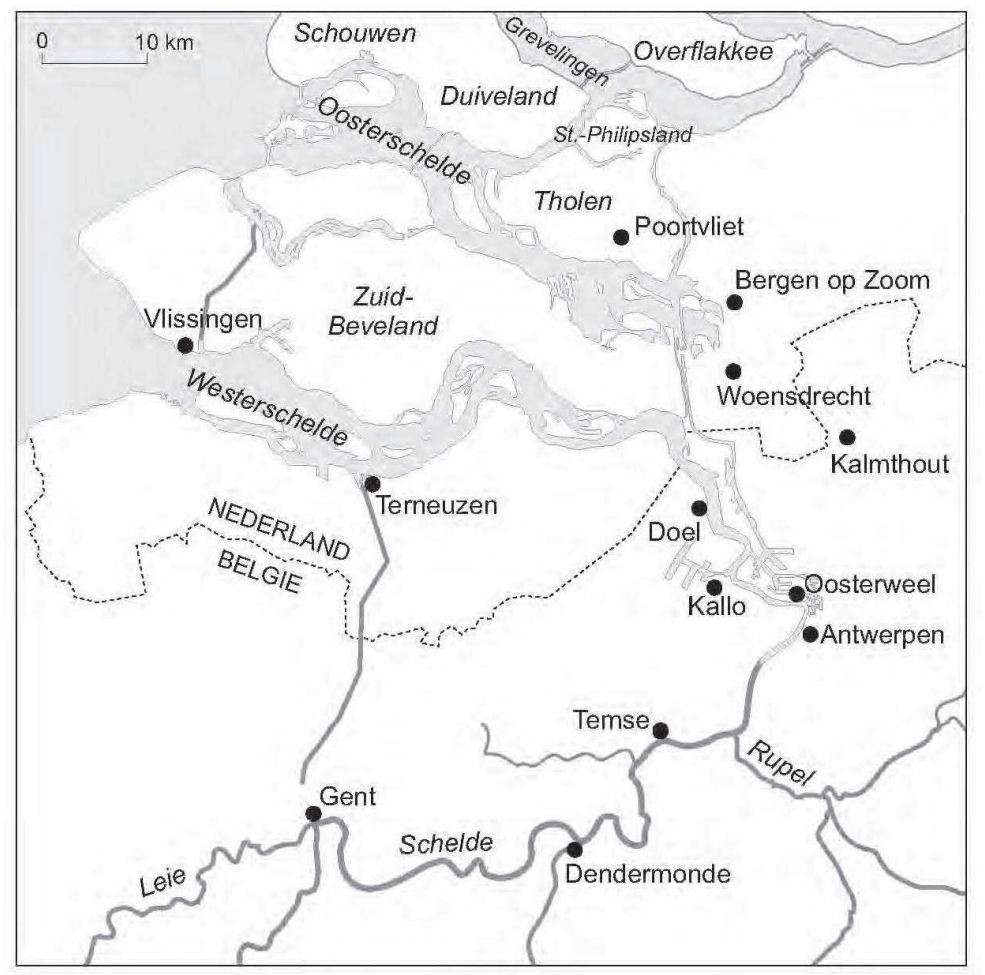

MEER PLAATSNAMEN ZIJN TE VINDEN OP Fig. 3.

\section{De Laatglaciale Schelde in Nederland}

Het Laatglaciaal, van ongeveer 15500 tot 11500 jaar geleden, vormt de overgangsperiode tussen de laatste ijstijd en de huidige warme tijd, het Holoceen. Tijdens het Laatglaciaal vonden belangrijke veranderingen in het landschap plaats, waarvan het resultaat dikwijls nog goed zichtbaar is.

De ligging en het uitzicht van de Laatglaciale Schelde zijn in België redelijk goed bekend, omdat de afzettingen en reliëfsvormen ervan aan of dichtbij de oppervlakte liggen. De Laatglaciale schelde wordt gekenmerkt door de aanwezigheid van fossiele meanderbochten, die aanzienlijk groter zijn dan die van de huidige Schelde (Fig. 2) en wijzen op piekdebieten die 3 tot 5 keer groter waren dan die van de huidige rivier (Kiden, 1991). Deze grootschalig-meanderende Schelde sneed zich enkele meter in ten opzichte van de verwilderde rivier die actief was tijdens de laatste fase van het WeichselPleniglaciaal. Hierdoor wordt de riviervlakte van deze Laatglaciale meanderende Schelde op vele plaatsen begrensd door een duidelijke steilrand, die meestal ook de rand vormt van de huidige overstromingsvlakte van de Schelde (Kiden en Verbruggen, 2001). Voorbeelden van grote meanderbochten, dikwijls met duidelijke kronkelwaardruggen ("point bars") zijn o.a. te vinden in Kalken en in Berlare (De Coster, 1982) (Fig. 2), maar zijn ook elders langs de Schelde en haar bijrivieren in het landschap zichtbaar. Stroomafwaarts van Dendermonde verdwijnen deze afzettingen en landvormen onder een dun dek van veen en Laat-Holocene klei, maar ook daar zijn de Laatglaciale 
beddingen aan de hand van boorgegevens te vervolgen, bv. bij Temse en Antwerpen (Mijs e.a., 1983; Kiden en Verbruggen, 1987; Kiden, 1989a; Kiden, 1991). Nog verder stroomafwaarts echter, vooral ten noorden van de Nederlandse grens, komen de Laatglaciale Schelde-afzettingen steeds dieper onder het maaiveld te liggen en worden ze moeilijker bereikbaar voor boringen. Dit is dan ook de hoofdreden waarom ze tot in het begin van de jaren 1990 in Nederland zo goed als onbekend waren. Wel had paleobotanisch onderzoek in oostelijk Zeeland op een aantal plaatsen gyttja's en rivierafzettingen van Laatglaciale of Vroeg-Holocene ouderdom aangetoond, die gelijkenis vertoonden met wat ook verder stroomopwaarts in België uit de Scheldevallei bekend was (zie bijvoorbeeld De Jong, 1966, 1967 en 1970). Het bleven echter verspreide gegevens waarvan het verband met de Schelde niet duidelijk was, en waarmee de rivierloop niet gereconstrueerd kon worden. Pas bij de kartering van het laatste blad van de geologische kaart van Zeeland, in het uiterste oosten van de provincie, kwam hierin meer klaarheid.

Figuur 2. De Schelde tussen Gent en Dendermonde, met de ligging van een aantal grote Laatglaciale paleomeanders en rivierduinmassieven.

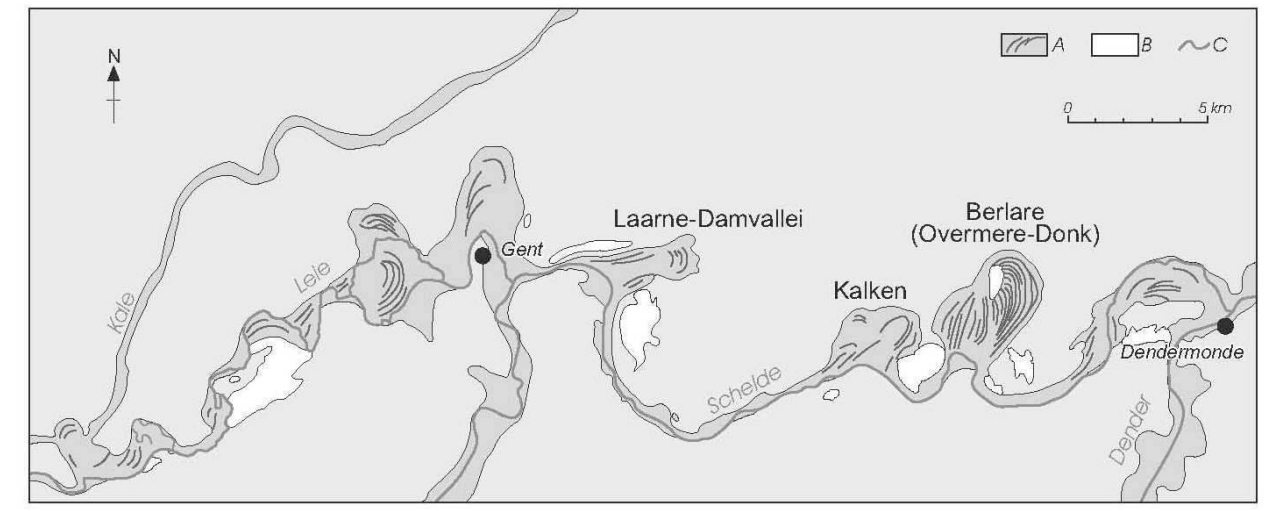

VERKLARINg: A. PALEOMEANDERS MET FOSSIELE KRONKELWAARDRUggEN; B. RIVIERDUINEN; C. HUIDIgE RIVIERLOPEN (NAAR KIDEN EN VERBRUggEN, 2001)

$4 \quad$ Aan de hand van een groot aantal boringen kon door Vos (1992) en Vos en Van Heeringen (1997) een gedetailleerde reconstructie gemaakt worden van het Pleistocene reliëf zoals dat waarschijnlijk aan het begin van het Holoceen in Zeeland bestond, dus voordat het door de steeds stijgende zeespiegel werd overstroomd en door diepe getijdengeulen werd versneden. Samen met een gelijkaardige kaart voor het Belgisch deel van het BenedenScheldedal ontstond zo een beeld van het reliëf op het einde van de laatste ijstijd in zuidwest-Nederland en in het Scheldedal stroomafwaarts van Antwerpen (Kiden, 1995) (Fig. 3). 
Figuur 3. Hoogteligging van het Pleistocene oppervlak langs de Schelde stroomafwaarts van Antwerpen, vóór de verdrinking door de Holocene zeespiegelstijging.

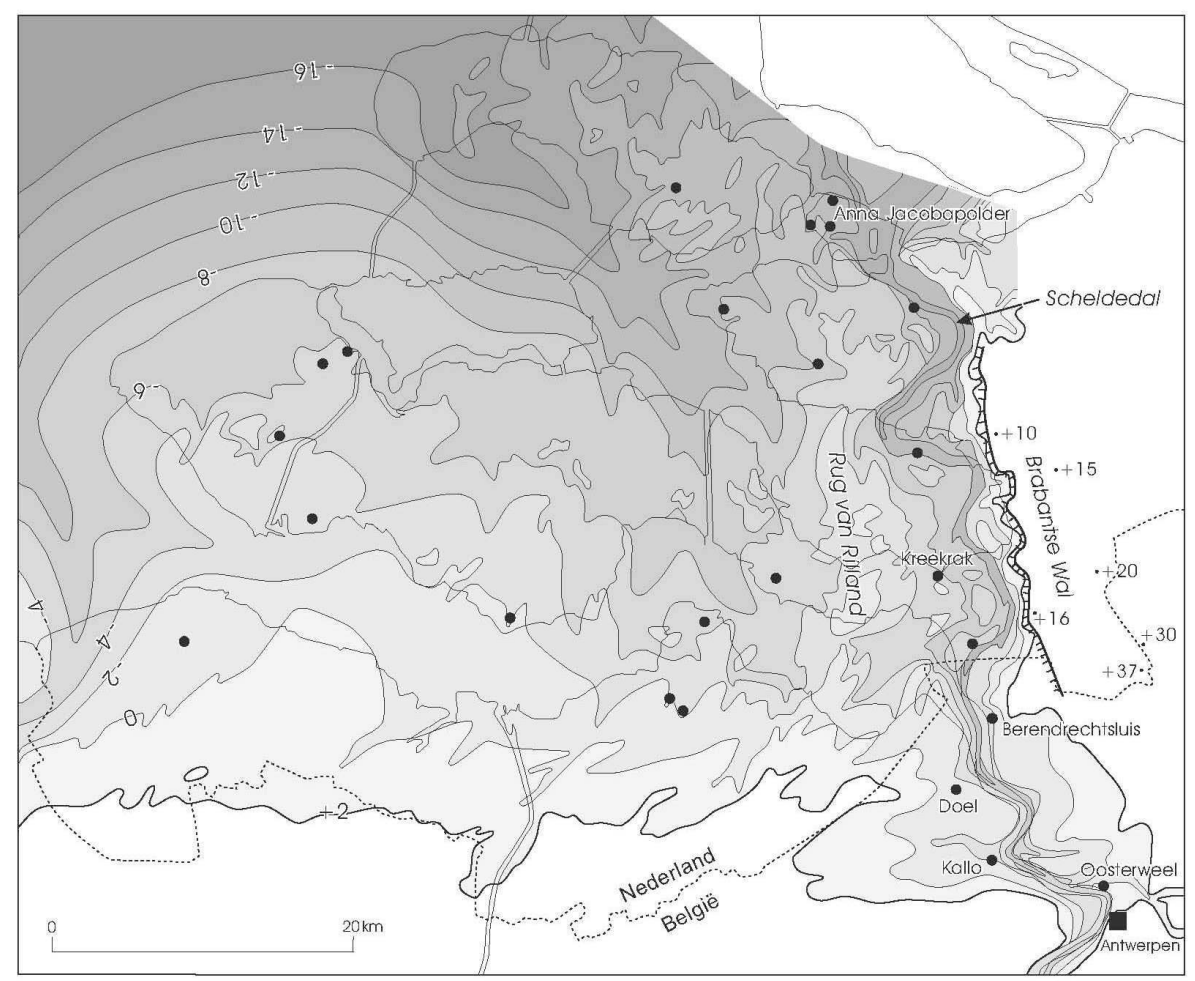

DONKERE KLEUREN geVen Een DIEPERE LIgging AAN. DE ZWARTE PUNTEN ZIJN LOCATIES VAN 14CDATERINGEN VAN DE BASIS VAN HET BASISVEEN OP HET PLEISTOCENE SUBSTRAAT, DIE WEERgEgEVEN WORDEN OP FIg. 5. HOOgTECIJFERS IN M TAW (TWEEDE ALgEMENE WATERPASSINg, ONgEVEER 2,33 M BENEDEN HET NEDERLANDSE PEIL NAP).

NAAR KIDEN, 1995. 
Figuur 4. De ligging van de verschillende Scheldelopen stroomafwaarts van Antwerpen sinds het einde van de laatste ijstijd. Ouderdommen BP zijn kalenderjaren voor heden.

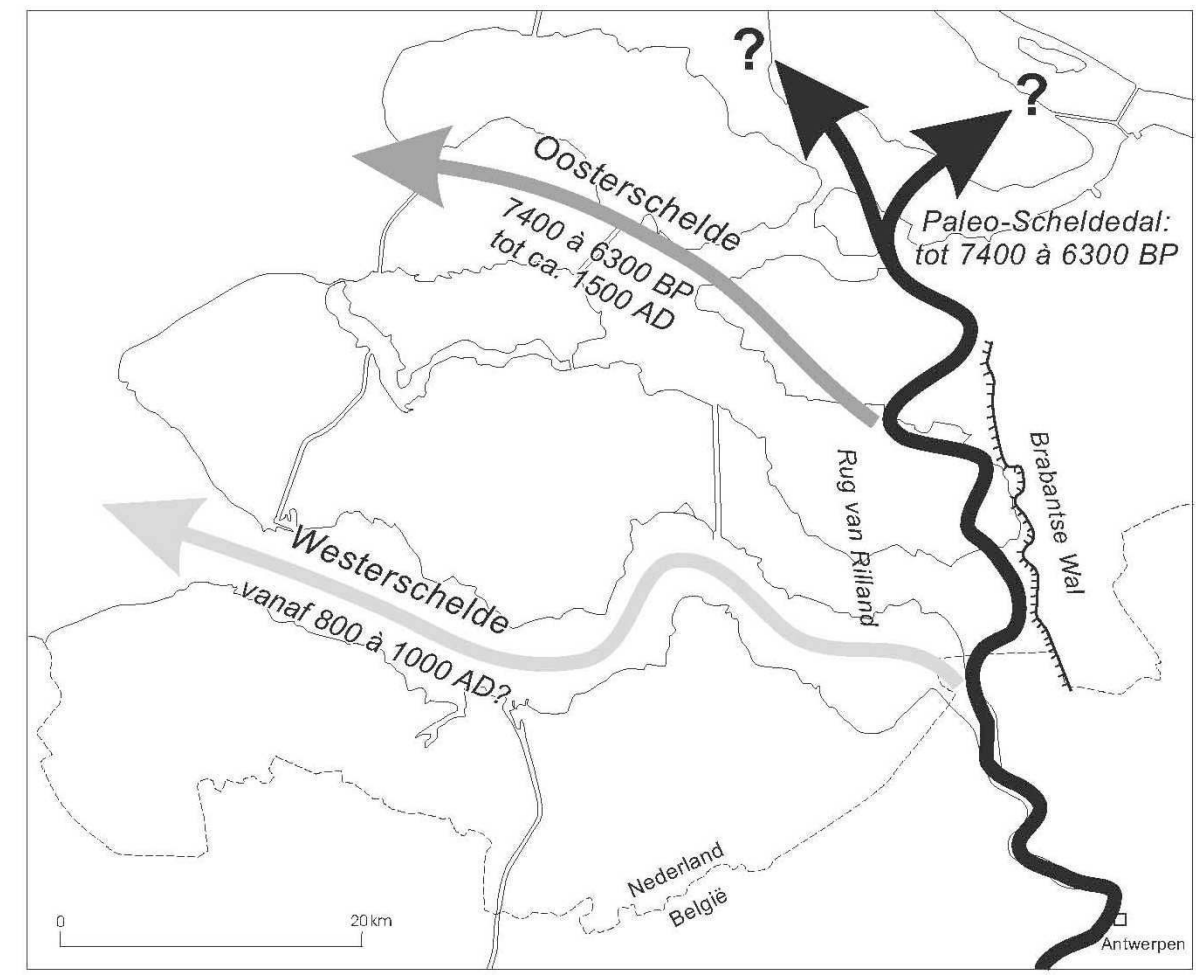

Deze reconstructie toont de voortzetting op Nederlands grondgebied van het LaatPleistocene dal van de Schelde. Het is duidelijk dat er op het einde van de laatste ijstijd nog helemaal geen sprake was van een Wester- of Oosterschelde (Fig. 4). De Scheldepaleovallei loopt in een aantal grote bochten door het oostelijk deel van Zuid-Beveland en Tholen naar Sint-Philipsland. Verder stroomafwaarts kan de toenmalige Scheldeloop vooralsnog niet vervolgd worden. Mogelijk liep ze verder noordelijk door Overflakkee, om ten zuidwesten van Rotterdam in het gemeenschappelijke dal van de Rijn en de Maas uit te monden. De Gans en van Gijssel (1996) veronderstellen een meer noordwestelijke richting vanaf Sint-Philipsland, ongeveer op de plaats van de Grevelingen tussen GoereeOverflakkee en Schouwen-Duiveland (Fig. 4). Een precieze reconstructie wordt bemoeilijkt doordat eventuele Laatglaciale of oudere Schelde-afzettingen in dit gebied bedolven liggen onder meer dan $20 \mathrm{~m}$ jongere sedimenten, of werden opgeruimd door de insnijding van recentere getijdegeulen en zeearmen.

Het Laat-Pleistocene Scheldedal is ingesneden tot een diepte van ongeveer $-6 \mathrm{~m}$ TAW te Antwerpen, $-10 \mathrm{~m}$ bij de Belgisch-Nederlandse grens en -16 $\mathrm{m}$ bij Anna Jacobapolder op Sint-Philipsland (Fig. 3). In Nederland ligt de paleovallei aan de voet van de Brabantse Wal, een prominente steilrand die tot $+20 \mathrm{~m}$ hoog is en bestaat uit Onder-Pleistocene estuariene afzettingen. Aan de westzijde wordt het Scheldedal begrensd door de relatief smalle, noord-zuid gerichte Rug van Rilland, waar de top van het Pleistoceen substraat een hoogte bereikt van $-4 \mathrm{~m}$. Ten westen van de Rug van Rilland heeft het Pleistoceen oppervlak een vlakke, amfitheater-achtige vorm en helt geleidelijk af naar het noordwesten en noorden.

7 Met de reconstructie van het Laatglaciale Scheldedal wordt ook duidelijk wat de bron was van het zand dat het grote duincomplex bovenop de Brabantse Wal vormde. Dit 
duingebied, waarvan de hoogste toppen meer dan $+30 \mathrm{~m}$ bereiken, strekt zich uit van ten noorden van Bergen op Zoom tot voorbij de Belgisch-Nederlandse grens in het zuiden en omvat ook het duingebied van de Kalmthoutse Heide op Belgisch grondgebied. Het bestaat in aanleg uit Laatglaciale rivierduinen zoals die ook verder stroomopwaarts langs de Schelde en bijrivieren in België worden aangetroffen (bv. bij Berlare, Fig. 2) (Mijs, 1974), of langs de Maas en de Rijn in Nederland. Tijdens het Holoceen zijn vele van deze rivierduincomplexen, meestal onder invloed van menselijk ingrijpen, opnieuw verstoven tot zogenaamde stuifzanden, waarbij dikwijls grote paraboolduinen werden gevormd.

Gestoken boringen in het Scheldedal in Nederland (bij voorbeeld ten westen van Bergen op Zoom onder de Oosterschelde) tonen aan dat de zandige Pleistocene rivierafzettingen grote hoeveelheden herwerkt Tertiair schelpenmateriaal bevatten. Dit materiaal is afkomstig uit schelpenrijke Laat-Tertiaire afzettingen die in het Antwerpse havengebied dichtbij het oppervlak komen (zie bijvoorbeeld Louwye e.a., 2004) en daar werden aangesneden door de Laat-Pleistocene Schelde. Ouderdomsbepaling van deze zandige rivierafzettingen met bijvoorbeeld luminiscentie-dateringen zou nieuw licht kunnen werpen op de ouderdom van de zogenaamde "Antwerpse Schelde" en daarmee mogelijk ook op het tijdstip van ontstaan van het "doorbraakdal van Hoboken" tussen Antwerpen en de Rupelmonding, waar de Schelde doorheen de cuesta van de Boomse Klei breekt (Tavernier en De Moor, 1974).

\section{De Holocene zeespiegelstijging in Zeeland: gegevens uit het Laat-Pleistocene Scheldedal}

Door het afsmelten van de grote landijskappen steeg tijdens en na het einde van de laatste ijstijd de zeespiegel snel: van meer dan $30 \mathrm{~m}$ onder het huidige zeeniveau rond 10000 jaar geleden tot $-7 \mathrm{~m} 7000$ jaar geleden (Fig. 5). Voor de reconstructie van de Holocene zeespiegelstijging gebruikte Jelgersma (1961) basisveendateringen uit het Nederlandse kustgebied. De dateringen uit Zeeland bleken aanzienlijk hoger te liggen dan dateringen van vergelijkbare ouderdom uit de rest van Nederland. Volgens Jelgersma (1961) kon dit verklaard worden door de geringere bodemdaling van Zeeland ten opzichte van de rest van Nederland, of door de grotere getijdenamplitude in Zeeland, waardoor het basisveen op een hoger niveau ten opzichte van het gemiddeld zeepeil gevormd kon zijn. Van de Plassche (1982) toonde bovendien aan dat het waarschijnlijk was dat op een aantal bemonsteringspunten van Jelgersma (1961) het basisveen zich meerdere meter boven de toenmalige zeespiegelstand had gevormd door grondwaterkwel op het slecht afwaterende Pleistoceen oppervlak. 
Figuur 5. De Holocene zeespiegelstijging in Zeeland, vergeleken met die in West-Nederland.

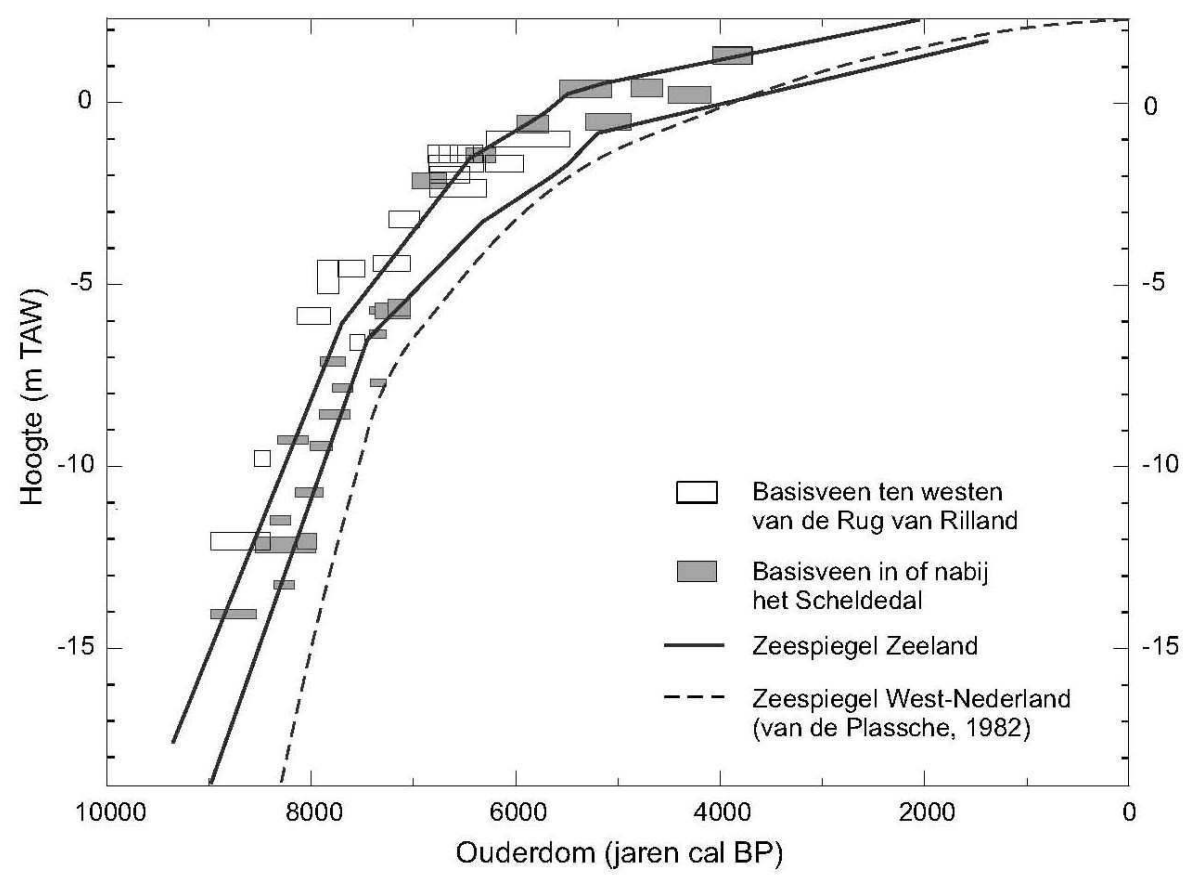

DE ZEESPIEgELCURVE VOOR ZEELAND IS WEERgEgEVEN ALS EEN FOUTEN-ENVELOPPE (NAAR VOS EN KIDEN, 2005). TEVENS ZIJN 14C-DATERINgEN AANgEgEVEN VAN BEgINNENDE BASISVEENgROEI IN HET SCHELDEDAL (gRIJZE RECHTHOEKEN) EN IN DE REST VAN ZEELAND (WITTE RECHTHOEKEN). DE LOCATIES VAN DEZE DATERINgEN ZIJN WEERgEgEVEN OP FIg. 3.

De hypothese van Van de Plassche (1982) werd bevestigd door meer recente basisveendateringen uit het Laatglaciale Scheldedal. Deze blijken consistent lager te liggen dan dateringen van vergelijkbare ouderdom van Jelgersma (1961) uit de rest van Zeeland (Fig. 5), en vormen bijgevolg een betere benadering voor de Holocene zeespiegelstijging (Kiden, 1995). Dit maakt het paleo-Scheldedal bij uitstek geschikt voor zeespiegelreconstructie. Dit heeft verschillende redenen. Omdat het dal het laagste deel was in het landschap zullen dateringen van de onderkant van het basisveen al vroeg de stijging van de zeespiegel registreren. Bovendien helde de grondwatertafel af naar het diep ingesneden Scheldedal, waardoor de kans kleiner is dat basisveengroei optrad ver boven de toenmalige zeespiegelstand (zoals het geval was op het vlakkere deel van het Pleistocene oppervlak ten westen van de Rug van Rilland, zie Fig. 5). Verder werd ook het rivierverhang minimaal zodra het gebied binnen de directe invloedssfeer van de zee kwam (zie onder).

$11 \mathrm{Na} 1995$ is een uitgebreide campagne opgezet om nieuwe basisveendateringen te verkrijgen uit het paleo-Scheldedal in Zeeland. Een aantal van deze nieuwe dateringen werd weergegeven in Fig. 5, 6 en 8. Deze nieuwste zeespiegelgegevens geven aan dat de curve voor de Holocene zeespiegelstijging in Zeeland weliswaar lager ligt dan werd aangenomen door Jelgersma, maar dat ze nog steeds consequent hoger ligt dan in Westen Noord-Nederland. Dit kan alleen maar verklaard worden doordat er een geringere bodemdaling plaatsvond in Zuidwest-Nederland (Kiden, 1995). Nauwkeurige analyse van zeespiegelgegevens uit het Belgisch-Nederlandse kustgebied heeft aangetoond dat een 
deel van dit verschil in bodemdaling te wijten is aan de tektonische opheffing van België ten opzichte van Nederland. Het grootste deel echter wordt veroorzaakt door glacio- en hydro-isostatische effecten als gevolg van het afsmelten van de Scandinavische ijskap na het maximum van de laatste ijstijd (Kiden e.a., 2002, Vos en Kiden, 2005). Door de gewichtsvermindering als gevolg van het afsmelten van de dikke ijskap komt de aardkorst omhoog in het gebied onder de voormalige ijskap. In de brede zone rond de vroegere ijskap vindt het omgekeerde plaats: daar zakt de aardkorst weg. De zone met maximale daling ligt waarschijnlijk in Noord-Nederland, Noord-Duitsland en onder het noordelijke Nederlands-Duitse deel van de Noordzee (Kiden e.a., 2002). België en Zuidwest-Nederland liggen ten zuiden van deze zone en hebben daardoor een geringere daling ondergaan.

\section{Holocene rivierevolutie en mariene invloed in de Beneden-Schelde}

\section{Een verdrinkend rivierdal}

Bij het begin van het Holoceen, rond 11500 jaar geleden, stond de zeespiegel nog te laag om enige invloed te hebben op de evolutie van de Beneden-Schelde in Zeeland en België (zie boven). Door de klimaatsverbetering en de sterke uitbreiding van de vegetatie na de laatste ijstijd werd de rivierafvoer lager en meer gelijkmatig. Het waterpeil in de rivier daalde en delen van de Laatglaciale beddingen begonnen zich op te vullen met gyttja en veen. Deze evolutie wordt geillustreerd door een recent onderzoek in het Laatglaciale/ Holocene Scheldedal bij Kreekrak in Zeeland (Bos et al., 2005). In een verlaten Laatglaciale rivierbedding vormde zich een ondiep meer, waarin gyttja en later veen werd afgezet. Bij het begin van het Holoceen verminderde de aanvoer van stromend (rivier)water in het meer, terwijl de grondwaterkwel toenam. De kwel was voornamelijk afkomstig van het nabijgelegen hoog van de Brabantse Wal. Ook elders aan de voet van de Brabantse Wal vormden zich kalkmeertjes door de sterke kalkrijke grondwaterkwel tijdens het Preboreaal en Boreaal.

De invloed van de zeespiegelstijging werd eerst voelbaar in het laagste, meest stroomafwaartse deel van de benedenloop in Nederland en drong langzaam stroomopwaarts door naargelang het zeepeil steeg. Reeds rond 8000 jaar geleden was brak water en zwakke getijdenwerking aanwezig in de Schelde tot bij de BelgischNederlandse grens (Vos en de Wolf, 1997) (Fig. 6). Ook in meer stroomopwaartse delen van de Beneden-Schelde was de invloed van de zeespiegelstijging merkbaar, zij het op onrechtstreekse wijze. De stijgende zeespiegel veroorzaakte daar een vermindering van het verval van de rivier en een versnelde grondwaterstijging, waardoor het veen in de riviervlakte sneller opgroeide (Kiden, 1991).

De Schelde vervolgde tijdens het eerste deel van het Holoceen nog steeds haar noordelijke loop aan de voet van de Brabantse Wal (Fig. 4). Rond 8000 jaar geleden mondde ze ten noorden van Tholen uit in een uitgestrekte brakwaterlagune aan de landzijde van een breed getijdengebied achter de toenmalige kustlijn, dat bestond uit slikken, schorren en getijdengeulen (Vos en Van Heeringen, 1997). 
Figuur 6. De Holocene evolutie van de mariene invloed in de Beneden-Schelde in België en Zuidwest-Nederland.

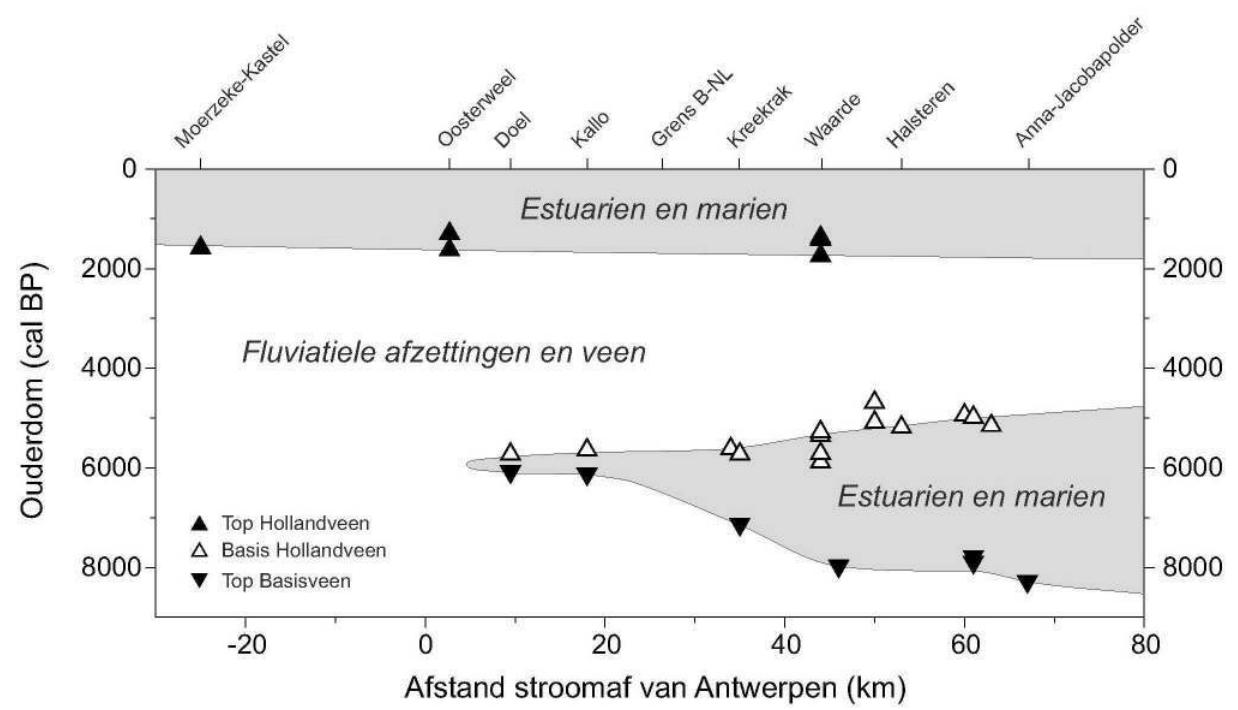

HET DIAgRAM IS gEBASEERD OP 14C-DATERINgEN VAN DE BOVEN- EN ONDERKANT VAN REgIONAAL VOORKOMENDE VEENLAgEN EN FLUVIATIELE EN MARIENE KLASTISCHE AFZETTINgEN, UITgEZET IN EEN LENGTEPROfIEL LANgS DE RIVIER. VEEN EN FLUVIATIELE AFZETTINGEN WORDEN GEVORMD IN EEN TERRESTRISCH EN/OF ZOETWATER-AFZETTINGSMILIEU, TERWIJL ESTUARIENE EN MARIENE AFZETTINGEN EEN GETIJDEN EN/OF BRAKWATERMILIEU VOORSTELLEN. DE OUDERDOM IS IN KALENDERJAREN VOOR HEDEN.

\section{Toenemende mariene invloed}

De voorloper van de huidige Oosterschelde ontstond in de periode tussen 7400 en 6300 voor heden. Een belangrijke getijdengeul ontwikkelde zich ongeveer op de plaats van de huidige Oosterschelde, erodeerde het ondertussen door de stijgende zeespiegel overstroomde laagste, noordelijke deel van de Rug van Rilland en maakte oostwaarts doorheen Tholen contact met de noordwaarts stromende Schelde. De Schelde ging gebruik maken van deze kortere verbinding met de zee in noordwestelijke richting (Fig. 4). De noordelijke loop raakte in onbruik en werd opgevuld met klei en veen (Vos en Van Heeringen, 1997).

Een belangrijke vaststelling was dat tussen 6000 en 5700 jaar geleden kortstondig brakwater-getijdeninvloed aanwezig was in de Beneden-Schelde op Belgisch grondgebied stroomafwaarts van Antwerpen, toen ook in Zeeland de mariene afzettingen hun maximale uitbreiding kenden (Fig. 6). In deze periode werd een laag brakwaterklei afgezet te Doel en Kallo (Minnaert en Verbruggen, 1986; Verbruggen en Denys, 1991). Deze afzettingen vormen de verst waargenomen uitbreiding van de mariene invloed in de Beneden-Schelde tijdens het Midden-Holoceen.

\section{Algemene veengroei}

Vanaf ongeveer 5700 jaar geleden nam de snelheid van de zeespiegelstijging af (Fig. 5) waardoor een kustbarrière werd opgebouwd met zeegaten die zich geleidelijk sloten. De doorstroomopening van de getijdengeulen verkleinde, waardoor de getijdenwerking landinwaarts sterk werd gedempt. Hierdoor verdween in de Beneden-Schelde stroomaf 
van Antwerpen ook de brakwater-getijdeninvloed (Fig. 6). Het slikken- en schorrengebied achter de kustbarrière in Zeeland verlandde en veranderde in een groot veengebied.

Op Nederlands grondgebied kronkelde de Schelde zich als een kleine rivier door het veen. Een oude Scheldeloop uit deze periode bij Poortvliet op Tholen is ongeveer $100 \mathrm{~m}$ breed en maximaal $7 \mathrm{~m}$ diep, en kende slechts zwakke of helemaal geen getijden (Vos en van Heeringen, 1997). De afmetingen komen overeen met die van riviergeulen uit de (getijdenloze) Boven-Schelde en uit de Beneden-Schelde vóór die aan getijdenwerking onderhevig was (zie onder). Langs de Beneden-Schelde stroomop van Antwerpen zijn in het veen weinig sporen van een rivierloop terug te vinden. Alleen zeldzame, dunne lenzen kleiig zand duiden op de aanwezigheid van stromend water. De Schelde had een zeer klein verval en stroomde langzaam door een uitgestrekt elzenbroek dat bijna de hele riviervlakte innam. De rivier had mogelijk een anastomoserend patroon (sensu Smith, 1983), met meerdere ondiepe, smalle beddingen en een geringe sedimentlading van kleiig en fijnzandig materiaal (Mijs e.a., 1983; Kiden, 1991). Het kleiig materiaal in suspensie werd bij overstromingen in de hele riviervlakte afgezet en geeft aan het veen een kleiig karakter.

\section{Hernieuwde mariene invloed}

Vanaf enkele eeuwen voor onze tijdrekening werd de beschermende kustbarrière plaatselijk doorbroken en nam de mariene invloed in Zeeland weer toe (Vos en van Heeringen, 1997). Zeegaten en getijdengeulen werden breder en dieper. Op de plaats van de huidige Westerschelde-monding ontstond waarschijnlijk een klein zeegat met getijdengeul-systeem, maar de Schelde mondde nog steeds via de Oosterschelde in zee uit en van een verbinding met de Westerschelde-in-aanleg was nog geen sprake (Fig. 4). Door de vergroting van de zeegaten nam de getijdenwerking in de Schelde toe, eerst stroomafwaarts en later ook meer stroomopwaarts. Naar het einde van de veenvorming toe kan in het veen een hernieuwde vervochtiging van het milieu worden vastgesteld, gepaard gaande met de aanvoer van brak water (Denys en Verbruggen, 1989). Stroomop van Antwerpen was echter geen brakwaterinvloed merkbaar.

Ongeveer vanaf het begin van onze tijdrekening veroorzaakten de toename van de getijdenwerking en de aanvoer van brak water het einde van de veenontwikkeling en de afdekking van het veen door een kleilaag (Fig. 6). Dat gebeurde niet overal tegelijk. In Zeeland stopte de veengroei op sommige plaatsen al rond de Romeinse tijd maar bleef het veen op andere plaatsen tot $600 \mathrm{AD}$ bleef doorgroeien (Vos en van Heeringen, 1997). Langs de Beneden-Schelde op Belgisch grondgebied eindigde de veengroei bij Doel bij het begin van onze tijdrekening (Minnaert en Verbruggen, 1986; Denys en Verbruggen, 1989), maar pas rond 500 à $600 \mathrm{AD}$ verder stroomopwaarts, in Oosterweel bij Antwerpen (Kiden, 1989b). Ook stroomop van Antwerpen kon het veen tot 500 à $600 \mathrm{AD}$ blijven doorgroeien (Verbruggen, 1971). Omdat de getijdenwerking op Belgisch grondgebied tot 1100 AD nog zeer gering was werd slechts een dun kleipakket op het veen afgezet (Denys en Verbruggen, 1989; Kiden, 1989b).

Het preciese begin van de getijdenwerking en mariene invloed in de Beneden-Schelde op Belgisch grondgebied is nog onderwerp van discussie. Volgens Verbruggen (2002) was er minstens vanaf de $3^{\text {de }}-4^{\text {de }}$ eeuw $A D$ toenemende mariene invloed en getijdenwerking merkbaar in de Schelde stroomaf van Antwerpen op Belgisch grondgebied. De bron van deze vroege mariene invloed was zeer waarschijnlijk de Oosterschelde-monding (Denys 
en Verbruggen, 1989). Het ontstaan van de Westerschelde als nieuwe verbinding van de Schelde met de zee kan immers op basis van de beschikbare geologische en historische gegevens gedateerd worden in de periode van ca. 800 tot $1100 \mathrm{AD}$ (Vos en van Heeringen, 1997). Volgens Vos en van Heeringen (1997) en Vos en de Wolf (1997) was er echter verder stroomafwaarts in de Oosterschelde, bij Poortvliet op Tholen, geen brak water aanwezig vóór $300 \mathrm{AD}$. De hypothese dat mariene invloed in de loop van de $4^{\text {de }}$ eeuw $\mathrm{AD}$ via de Oosterschelde tot Belgisch grondgebied doordrong is met alle bovenstaande feiten in overeenstemming, hoewel misschien nog kleine dateringsverschillen overblijven. Vervochtiging in het veen vóór die tijd, zoals vastgesteld door Denys en Verbruggen (1989), zou dan mogelijk te wijten kunnen zijn aan een toenemende zoetwatergetijdeninvloed, als voorloper van brakwater-getijdenwerking. Het is ook de vraag of de gebruikte milieureconstructies niet hun detectielimieten naderen van bv. zoet- en brakwater-invloed, en of door de (meestal onvoldoende bekende) paleogeografie rond de onderzochte sites in relatie tot de toenmalige rivierbedding geen significante verschillen mogelijk zijn tussen de saliniteit van het lokale milieu en de condities in de rivierloop zelf, waardoor de brakwater-invloed in de rivier zelf onderschat zou kunnen worden.

Langs de Beneden-Schelde zijn restanten van de rivier uit de periode rond het begin van de getijdenwerking slechts zelden bewaard gebleven, omdat de rivierbedding later sterk is verbreed door de steeds krachtiger wordende getijden-erosie. Hierdoor werden de sporen van deze oude Scheldeloop meestal opgeruimd. Het mooiste voorbeeld is de "Oude Schelde" bij Temse, die in de $13^{\text {de }}$ eeuw werd afgesneden van de huidige Schelde (Mees, 1914; Mijs e.a., 1983; Kiden, 1989a). De Oude Schelde had een gemiddelde breedte van ongeveer $75 \mathrm{~m}$, wat erop wijst dat ze nog weinig of geen getijdenwerking kende.

\section{De ontwikkeling van het Westerschelde-estuarium}

Evenals het begin van de mariene invloed vormt het preciese tijdstip van ontstaan van de Westerschelde als verbinding van de Schelde met de zee een probleem. Dit is misschien zelfs definitief onoplosbaar omdat de afzettingen uit de beginfase van de ontwikkeling van de Westerschelde allemaal opgeruimd zijn door de latere sterke verbreding en verdieping van het estuarium. Het enige wat met zekerheid uit historische bronnen kan worden afgeleid is dat de Westerschelde al bestond in $1183 \mathrm{AD}$, en dat de oostelijke Westerschelde toen een aanzienlijke zeearm met getijdenwerking was (Augustyn, 1986). In elk geval blijft gedurende een hele tijd na het ontstaan van de Westerschelde de Oosterschelde de belangrijkste verbinding van de Schelde met de zee (Fig. 4). De Westerschelde won steeds meer aan belang ten opzichte van de Oosterschelde, maar was pas rond het einde van de $15^{\text {de }}$ eeuw breed en diep genoeg om goed toegankelijk te zijn voor het toenmalige scheepvaartverkeer naar Antwerpen. Hierna begon de verbinding tussen de Westerschelde en de Oosterschelde snel te verzanden. Ze verdween in 1867, toen bij Woensdrecht een spoorwegdijk werd aangelegd die beide Schelde-armen definitief van elkaar scheidde.

De getijdenwerking in de Schelde is sinds 1100 à 1200 AD steeds sterker geworden en verder stroomopwaarts doorgedrongen. Dit werd veroorzaakt door natuurlijke processen, zoals de verbreding en verdieping van de Westerschelde en de opslibbing van het getijdengebied, en door menselijke ingrepen. Vooral het begin van de bedijkingen in de eerste helft van de $12^{\text {de }}$ eeuw (Guns, 1975; Leenders, 1985) had een belangrijk invloed, 
omdat hierdoor het overstromings-areaal bij hoog water sterk verkleinde, wat het hoogwaterpeil in de rivier verhoogde. Vooral sinds de $16^{\text {de }}$ eeuw is het tijverschil snel toegenomen (Fig. 7). Het bereikt nu meer dan $5 \mathrm{~m}$ in de omgeving van de Rupelmonding stroomop van Antwerpen. Het getijdebiet en de eb- en vloed-stroomsnelheid zijn ook groter geworden. Hierdoor nam de erosie in de Scheldebedding toe waardoor ze steeds dieper en breder werd. Zo is bij Temse de rivier nu tot $10 \mathrm{~m}$ diep en heeft een breedte van $250 \mathrm{~m}$, aanzienlijk meer dan de $75 \mathrm{~m}$ brede Oude Schelde uit de $12^{\text {de }}-13^{\text {de }}$ eeuw op dezelfde plaats (zie boven). Door de voortdurende stijging van het hoogwaterpeil slibden de slikken en schorren steeds hoger op en moesten de dijken herhaaldelijk opgehoogd en verstevigd worden. Dit kon nochtans niet verhinderen dat bij stormvloeden soms catastrofale overstromingen plaatsvonden, waarvan de gevolgen nu nog duidelijk in het landschap zichtbaar zijn (wielen, kreken, kraagdijken).

Figuur 7. Historische evolutie van het tijverschil in de Beneden-Schelde en Westerschelde.

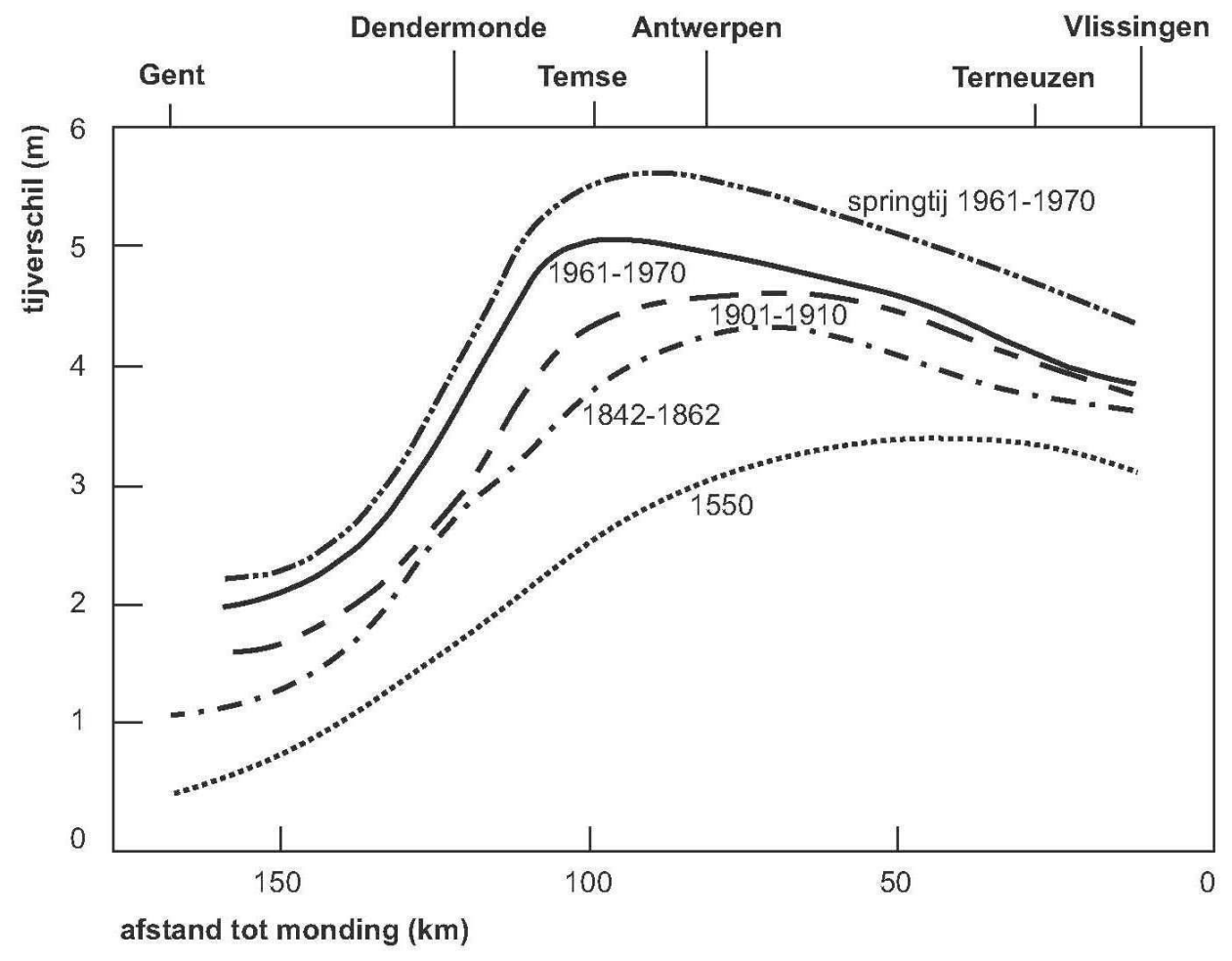

NAAR COEN, 1988 
mogelijke factor zijn de uitgebreide baggerwerken van de laatste vijftig jaar. Deze dienen om de bevaarbaarheid te verbeteren en de Antwerpse haven toegankelijk te maken voor steeds grotere schepen. Omdat de Scheldebedding daarbij verdiept wordt, zou de getijgolf makkelijker het estuarium kunnen binnendringen, waardoor de gemiddelde hoogwaterstanden stijgen. Het Schelde-estuarium bezit bovendien ook een zeer grote eigen dynamiek, waardoor het op diverse manieren en met min of meer grote vertraging kan reageren op natuurlijke of door de mens veroorzaakte veranderingen. Het onderlinge belang en wisselwerking van de hierboven genoemde factoren blijkt tot nu toe lastig in te schatten en in modellen te vatten.

\section{Evolutie van de riviergradiënt onder invloed van de zeespiegelstijging}

De gradiënt- of verhanglijn van een rivier helt in stroomafwaartse richting af naar een bepaald basisniveau. In het geval de rivier in zee uitmondt is dit het zeeniveau. Als het zeeniveau verandert, bij voorbeeld door de Holocene zeespiegelstijging, zal ook het lengteprofiel van de rivier zich aanpassen. Het verhang van de Beneden-Schelde was groot in het Laatglaciaal en het begin van het Holoceen bij een lage zeespiegelstand, maar nam af door de stijging van het zeepeil. Dit wordt geillustreerd in Fig. 8. In deze figuur worden een aantal lengteprofielen weergegeven voor de Beneden-Schelde op verschillende tijdstippen tijdens het Holoceen. Tevens is de diepteligging van de thalweg van het ingesneden Laat-Pleistocene Scheldedal uitgezet tegen de afstand ten opzichte van Antwerpen (zie ook Kiden, 1991). De Holocene gradiëntlijnen werden geconstrueerd door interpolatie van een aantal dateringen van beginnende basisveengroei op het Pleistocene substraat. Het begin van basisveengroei geeft de positie van de gemiddelde grondwaterstand aan. In een riviervlakte vormt het lengteprofiel van de gemiddelde grondwaterstand een benadering voor de verhanglijn van de rivier zelf (Van Dijk e.a., 1991). De op deze manier in Fig. 8 geconstrueerde riviergradiëntlijnen werden stroomafwaarts verbonden met het toenmalige zeeniveau (zie Fig. 5, "zeespiegel Zeeland"). 
Figuur 8. Evolutie van de riviergradiënt van de Beneden-Schelde in België en Zuidwest-Nederland tijdens het Holoceen.

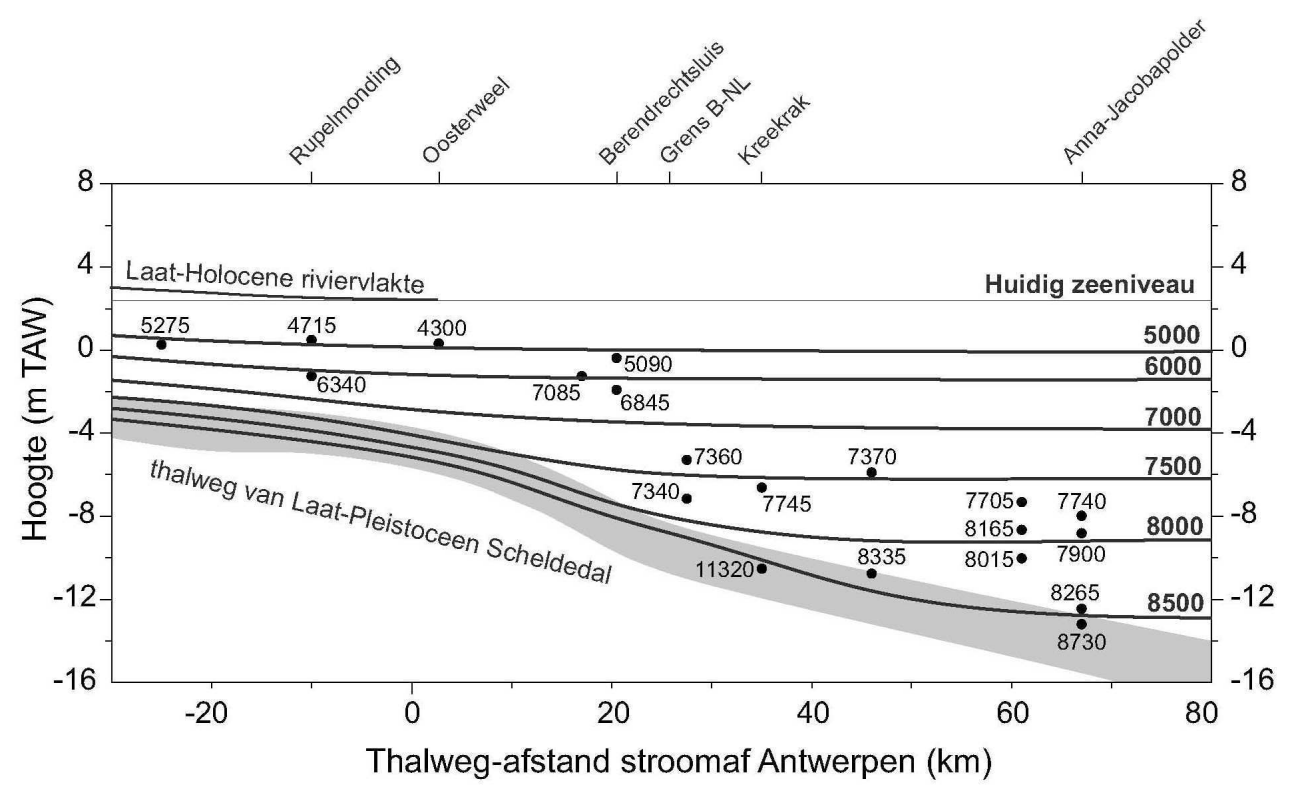

DE OUDERDOMMEN BIJ DE DATAPUNTEN gEVEN gECALIBREERDE 14C-JAREN WEER. VOOR UITLEg ZIE TEKST.

Uit Fig. 8 blijkt dat de Laatglaciale thalweg van de Beneden-Schelde een licht convexe vorm vertoont in de omgeving van Antwerpen. Dit werd mogelijk veroorzaakt door de aanwezigheid van een lokale erosiebasis, gevormd door erosie-bestendige Tertiaire afzettingen op geringe diepte in het doorbraakdal van Hoboken en in het rivierdal bij Antwerpen (Boomse Klei en Mio-Pliocene schelprijke mariene afzettingen) (Kiden, 1991). Het oorspronkelijke verhang van de Vroeg-Holocene rivier is overgeërfd van de zeewaartse helling van de Laatglaciale thalweg. De latere invloed van de Holocene zeespiegelstijging blijkt uit de verhoging van de opeenvolgende riviergradiëntlijnen van $8500,8000,7500,7000,6000$ en 5000 jaar geleden. Dit geeft aan dat de zeespiegelstijging vooral vóór 6000 voor heden een snelle stijging van het grondwater in de riviervlakte en van de rivierverhanglijn veroorzaakte. De grondwaterstijging werd bijgehouden werd door sterke veengroei in de riviervlakte van de Beneden-Schelde. Omdat de Schelde een geringe sedimentlading had werd in dit veenpakket erg weinig riviersediment afgezet, in tegenstelling tot het benedenstroomse deel van het Rijn-Maasdal in Nederland, waar de ophoging van de rivierverhanglijn onder invloed van de Holocene zeespiegelstijging werd bijgehouden door de afzetting van aanzienlijke hoeveelheden klastisch materiaal.

Het stroomafwaartse deel van de verhanglijnen in Fig. 8 vertoont een sterke afvlakking. In dit deel staat de rivier onder rechtstreekse invloed van de zee (Van Dijk e.a., 1991). Het knikpunt waar de hellende verhanglijn overgaat in het vlakke deel verschuift tussen 8500 en 6000 jaar geleden ongeveer $60 \mathrm{~km}$ stroomopwaarts, van Anna-Jacobapolder tot in de omgeving van Antwerpen. Dit valt samen met het eerste binnendringen van de mariene invloed in de Schelde ten gevolge van de toen nog relatief snelle zeespiegelstijging. Mariene invloed was inderdaad aanwezig in de Belgische Scheldepolders stroomaf van Antwerpen rond 6000 jaar geleden (zie boven, en Fig. 6).

31 Vanaf 6000 jaar geleden wordt het rivierverhang zeer klein, en blijven de gradiëntlijnen nagenoeg vlak in het deel van de Schelde stroomaf van Antwerpen. Dit komt overeen met 
een lange periode van algemene veengroei in het kustgebied in Zeeland en in de Scheldevlakte (zie boven, en Fig. 6). Dit werd veroorzaakt door een sterke landinwaartse demping van de getijdenwerking. In een dergelijke situatie is het zelfs mogelijk dat het vloedpeil in stroomopwaartse richting lager wordt. Dit wordt ook wel het "vloedkomeffect" genoemd (Van Veen, 1950; Zonneveld, 1960; Van de Plassche, 1982). Het is het gevolg van een sterke vermindering van de energie van de getijgolf door wrijving, en de aanwezigheid van een groot overstromingsareaal tussen het hoog- en het laagwaterniveau, waardoor in landwaartse richting de getijgolf aan hoogte verliest en het tijverschil sterk afneemt (Van de Plassche, 1984). Dit was ook het geval in de Schelde. In de periode tussen ca. 5000 jaar geleden en de Romeinse tijd vond stroomopwaarts van Antwerpen veengroei plaats op een peil tussen hoogwater op zee en gemiddeld zeeniveau, zodat aangenomen moet worden dat het hoogwaterpeil op zee hoger was dan het lokale gemiddelde rivierpeil (Kiden, 1989b; Kiden, 1991).

De toename van de getijdenwerking in de Beneden-Schelde na de Romeinse tijd en vooral na ca. 1100 AD (zie boven, en Fig. 6) is te verklaren door het verdwijnen van dit "vloedkom-effect". Eerst gebeurde dit op een natuurlijke manier, door de opening van de kustbarrière en het breder en dieper worden van de zeegaten en getijdengeulen, waaronder de Westerschelde. Later ging de mens hieraan meewerken: de overstroombare oppervlakte tussen hoog- en laagwaterpeil werd sterk verminderd door bedijkingen en inpolderingen, en door baggerwerken vanaf het midden van de $20^{\text {ste }}$ eeuw werd de doorstroomopening van de Scheldebedding vergroot en de wrijvingsweerstand verminderd.

Concluderend kunnen we stellen dat de toename van de mariene invloed tot een eerste maximum ca. 6000 geleden het gevolg was van het binnendringen van de snel stijgende zee in het diep ingesneden Scheldedal. Vanaf dan blijft een groot deel van de BenedenSchelde, zeker tot Antwerpen, binnen de invloedssfeer van de zee. De hierop volgende vermindering van de mariene invloed, gevolgd door een nieuwe toename tijdens de laatste 2000 jaar, zijn vooral veroorzaakt door paleogeografische wijzigingen in het mondingsgebied van de Schelde. Deze veranderingen beïnvloeden de mate waarin de getijdenwerking gedempt of juist versterkt wordt in stroomopwaartse richting. De langzaam doorgaande zeespiegelstijging speelt hierbij een veel minder belangrijke rol. Om de evolutie van de Beneden-Schelde tijdens de laatste 1000 jaar te verklaren is het dan ook niet nodig om te veronderstellen dat het zeepeil vóór de sterke toename van de getijdenwerking significant lager stond dan nu (cfr. Mijs e.a., 1983).

\section{BIBLIOGRAPHIE}

AUGUSTYN B. (1986), "Integratie van natuurwetenschappelijke en historische bronnen voor de ontginningsgeschiedenis van het zuidoostelijke Westerscheldegebied", Rotterdam Papers, V, pp. 137-146, Rotterdam. 
BOS J.A.A., HUISMAN D.J., KIDEN P., HOEK W.Z. \& VAN GEEL B. (2005), “Early Holocene environmental change in the Kreekrak area (Zeeland, SW-Netherlands): a multi-proxy analysis", Palaeogeography, Palaoeclimatology, Palaeoecology, 227, pp. 259-289, Elsevier.

COEN J. (1988), “Ontstaan en ontwikkeling van de Westerschelde”, Water, 46/1, pp. 156-162.

DE COSTER R. (1982), "De evolutie van de oude Scheldemeander te Berlare", De Aardrijkskunde, 1982/4, pp. 317-332.

DE GANS W. \& VAN GIJSSEL K. (1996), “The Late Weichselian morphology of the Netherlands and its influence on the Holocene coastal development", Mededelingen Rijks Geologische Dienst, 57, pp. 11-25, Haarlem, Rijks Geologische Dienst.

DE JONG J. (1966), “Pollenanalytisch onderzoek van een tweetal boringen (Holoceen en Laatglaciaal) uit de omgeving van Ossendrecht", Intern Rapport 448, Afdeling Paleobotanie Kenozoicum, Haarlem, Rijks Geologische Dienst, 3 p.

DE JONG J. (1966), “Aanvullend pollenanalytisch onderzoek aan boringen (Holoceen en Laatglaciaal) uit de omgeving van Ossendrecht”, Intern Rapport 448a, Afdeling Paleobotanie Kenozoicum, Haarlem, Rijks Geologische Dienst, 4 p.

DE JONG J. (1966), “Pollenanalytisch onderzoek van materiaal afkomstig uit de bouwput voor de aanleg van een sluis in het Krekerak", Intern Rapport 558, Afdeling Paleobotanie Kenozoicum, Haarlem, Rijks Geologische Dienst, 4 p.

DENYS L. \& VERBRUGGEN C. (1989). "A case of drowning - the end of subatlantic peat growth and related palaeoenvironmental changes in the lower Scheldt basin (Belgium) based on diatom and pollen analysis", Review of Palaeobotany and Palynology, 59, pp. 7-36, Elsevier.

GUNS P. (1975), Historische evolutie van het polderlandschap langs de linker Schelde-oever, 135 p., Borgerhout, Ministerie van Openbare Werken, Bestuur der Waterwegen, Waterbouwkundig Laboratorium.

JELGERSMA S. (1961), "Holocene sea-level changes in the Netherlands", Mededelingen Geologische Stichting, C-IV (7), 100 p.

KIDEN P. (1989a), "Temse en de Schelde: de geomorfologische achtergrond”, in THOEN H. (red.) Temse en de Schelde: Van IJstijd tot Romeinen, pp. 13-27, Brussel, Gemeentekrediet.

KIDEN P. (1989b), "Holocene water level movements in the lower Scheldt perimarine area”, Professional Paper Geologische Dienst van België, 241, 6, pp. 1-19.

KIDEN P. (1991), “The Lateglacial and Holocene evolution of the Middle and Lower River Scheldt, Belgium”, in STARKEL L., GREGORY K.J. \& THORNES J.B.(RED.), Temperate Palaeohydrology, pp. 283-299, Chichester, Wiley.

KIDEN P. (1995), "Holocene relative sea-level change and crustal movement in the southwestern Netherlands", Marine Geology, 124, pp. 21-41.

KIDEN P., DENYS L. \& JOHNSTON P. (2002), "Late Quaternary sea-level change and isostatic and tectonic land movements along the Belgian-Dutch North Sea coast: geological data and model results", Journal of Quaternary Science, 17, pp. 535-546.

KIDEN P. \& VERBRUGGEN C. (1987), "Het landschap in het Antwerpse sinds de laatste ijstijd”, in WARMENBOL E. (red.), Het ontstaan van Antwerpen: feiten en fabels, pp. 9-18, Antwerpen, Antwerpse Vereniging voor Bodem- en Grotonderzoek.

KIDEN P. \& VERBRUGGEN C. (2001), “Het verhaal van een rivier: de evolutie van de Schelde na de laatste ijstijd”, Publicaties van het Provinciaal Archeologisch Museum van Zuid-Oost-Vlaanderen - Site 
Velzeke Gewone Reeks, nr. 4, pp. 11-35, Velzeke, Provinciaal Archeologisch Museum van Zuid-OostVlaanderen.

LEENDERS K.A.H.W. (1985), "De Antwerpse polder in de middeleeuwen: ontginning, bedijking en overstromingen", Tijdschrift van de Belgische Vereniging voor Aardrijkskundige Studies, 54, pp. 43-77.

LOUWYE S., HEAD M.J. \& DE SCHEPPER S. (2004), "Dinoflagellate cyst stratigraphy and palaeoecology of the Pliocene in northern Belgium, southern North Sea Basin", Geological Magazine, 141 (3), pp. 353-378, Cambridge, Cambridge University Press.

MEES J. (1914), "La formation du Vieil Escaut", Annales de la Fédération Archéologique et Historique de Belgique, 1, pp. 241-250.

MIJS M. (1974), "Bijdrage tot de geomorfologie van het duinlandschap van de Kalmthoutse Heide”, Werken, nr. 7, pp. 1-88, Brussel, Ministerie van Landbouw, Bestuur van Waters en Bossen, Dienst Domaniale Natuurreservaten en Natuurbescherming.

MIJS M., GULLENTOPS F., JANSSENS P., WUYTACK M.J. \& STINISSEN H.(1983), "De holocene evolutie van de alluviale vlakte van de Beneden-Schelde", Tijdschrift van de Belgische Vereniging voor Aardrijkskundige Studies, 52, pp. 7-33.

MINNAERT G. en VERBRUGGEN C. (1986), "Palynologisch onderzoek van een veenprofiel uit het Doeldok te Doel”, Bijdragen Archeologische Dienst Waasland, 1, pp. 201-208, Sint-Niklaas, Archeologische Dienst Waasland.

SMITH D.G. (1983), “Anastomosed fluvial deposits: modern examples from Western Canada”, in COLLINSON J.D. \& LEWIN J. (red.), Modern and ancient fluvial systems, pp. 155-168, Special Publication of the International Association of Sedimentologists no. 6, Oxford, Blackwell Scientific Publications.

TAVERNIER R. \& DE MOOR G. (1974), "L'évolution du Bassin de l'Escaut”, in MACAR P. (red.), L'évolution des bassins fluviaux de la Mer du Nord méridionale, pp. 159-231, Liège, Colloque du Centenaire de la Société Géologique de Belgique.

VAN DE PLASSCHE O. (1982), "Sea-level change and water-level movements in the Netherlands during the Holocene”, Mededelingen Rijks Geologische Dienst, 36-1, pp. 1-93.

VAN DE PLASSCHE O. (1984), "Causes of a late-Atlantic swamp-forest submergence in the central Rhine/Meuse delta”, in MÖRNER N.-A., KARLÉN W. (red.), Climatic Changes on a Yearly to Millenial Basis, pp. 205-214, Dordrecht, Reidel.

VAN DIJK G.J., BERENDSEN H.J.A. en ROELEVELD W. (1991), “Holocene water level development in The Netherlands' river area; implications for sea-level reconstruction”, Geologie en Mijnbouw, 70, pp. 311-326.

VAN VEEN J. ( 1950), “Eb- en vloedschaarsystemen in de Nederlandse getijwateren”, Tijdschrift Koninklijk Nederlands Aardrijkskundig Genootschap, $2^{\text {de }}$ Reeks 67, pp. 303-350.

VERBRUGGEN C. (1971), Postglaciale landschapsgeschiedenis van zandig-Vlaanderen. Botanische, ecologische en morfologische aspecten op basis van palynologisch onderzoek, Doctoraatsproefschrift, Rijksuniversiteit Gent, 440 p.

VERBRUGGEN C. (2002), "Het ontstaan van de Westerschelde”, in DE KRAKER A.M.J. (red.), De Westerschelde, een water zonder weerga, pp. 9-16, Kloosterzande, Drukkerij Duerinck.

VERBRUGGEN C. \& DENYS L. (1991), "Early tidal influence on the Lower Schelde, Belgium", Aardkundige Mededelingen, 6, pp. 167-169, Katholieke Universiteit Leuven, Leuven. 
VOS P.C. (1992), Toelichting kaartblad 43/49 West en 49 Oost - Concept toelichting 43/49 West: holocene deel, RGD-Rapport 1454, 41 p., Haarlem, Rijks Geologische Dienst.

VOS P.C. \& DE WOLF H. (1997), "Palaeo-environmental diatom study of the Holocene deposits of the Province of Zeeland (SW Netherlands)", Mededelingen Nederlands Instituut voor Toegepaste Geowetenschappen TNO, 59, pp. 111-141, Utrecht, Nederlands Instituut voor Toegepaste Geowetenschappen TNO.

VOS P.C. \& KIDEN P. (2005), “De landschapsvorming tijdens de Steentijd”, Archeologie 11/12, pp. 7-37, Stichting Archeologie.

VOS P.C. \& VAN HEERINGEN R.M. (1993), The impact of environmental changes on the occupation history in the southwestern coastal area of the Netherlands (province of Zeeland), RGD-Rapport 1459, 61 p., Haarlem, Rijks Geologische Dienst.

VOS P.C. \& VAN HEERINGEN R.M. (1997), "Holocene geology and occupation history of the province of Zeeland", Mededelingen Nederlands Instituut voor Toegepaste Geowetenschappen TNO, 59, pp. 5-109, Utrecht, Nederlands Instituut voor Toegepaste Geowetenschappen TNO.

ZONNEVELD I.S. (1960), “De Brabantse Biesbosch”, Mededelingen Stichting Bodemkartering Bodemkundige Studies, 4, Wageningen, 396 p.

\section{RÉSUMÉS}

Deze bijdrage geeft een overzicht van de evolutie van de Beneden-Schelde in België en ZuidwestNederland tijdens het Laatglaciaal en het Holoceen, met speciale aandacht voor recente ontwikkelingen in het onderzoek. Tijdens het Laatglaciaal loopt de Schelde in Nederland in een diep dal in noordelijke richting. Als gevolg van de Holocene zeespiegelstijging dringt de zee dit dal binnen, waardoor het rivierverhang sterk vermindert. Rond 6000 jaar geleden kent de mariene invloed in Zeeland een eerste maximum en reikt dan tot op Belgisch grondgebied. Hierna neemt de mariene invloed sterk af en ontwikkelt zich achter de kustbarrière een uitgestrekt veengebied. Rond het begin van onze tijdrekening vergroot de mariene invloed weer. De getijden in de Schelde nemen langzaam toe en de veengroei stopt. Sinds ca. 1100 AD is de getijdenamplitude in de Schelde sterk toegenomen door het ontstaan en ontwikkeling van de Westerschelde en door menselijke ingrepen (bedijkingen en $20^{\text {ste }}$ eeuwse baggerwerken).

This paper gives an overview of the evolution of the Lower River Schelde in Belgium and the southwestern Netherlands, with special reference to recent research results. During the Lateglacial the Scheldt in The Netherlands occupies a deeply incised palaeovalley which runs in a northerly direction. In the course of the Holocene sea-level rise, the sea gradually invades this valley, resulting in a strong reduction in river gradient. Around 6000 years ago the marine influence in Zeeland reaches a first maximum and is even felt on Belgian territory. Subsequently marine influence wanes and in the area behind the coastal barrier extensive peat growth takes place. Around the beginning of our era marine influence intensifies again, causing a slow increase of the tides in the Scheldt River and the end of the peat growth. Since ca. 1100 AD tidal amplitude has grown considerably as a result of the development of the Westerschelde and human interference (embankments and $20^{\text {th }}$-century dredging). 
INDEX

Trefwoorden rivierontwikkeling, zeespiegelstijging, mariene invloed, riviergradiënt, Laatglaciaal, Holoceen, Schelde, België, Nederland

Keywords : river evolution, sea-level rise, marine influence, river gradient, Lateglacial, Holocene, Scheldt, Belgium, The Netherlands

\section{AUTEUR}

\section{PATRICK KIDEN}

TNO Bouw en Ondergrond - Geological Survey of The Netherlands, Patrick.Kiden@tno.nl 